Tropical Journal of Pharmaceutical Research March 2016; 15 (3): 441-445

ISSN: 1596-5996 (print); 1596-9827 (electronic)

(C) Pharmacotherapy Group, Faculty of Pharmacy, University of Benin, Benin City, 300001 Nigeria.

All rights reserved.

Available online at http://www.tjpr.org

Original Research Article

http://dx.doi.org/10.4314/tjpr.v15i3.2

\title{
Preparation of Edible Corn Starch Phosphate with Highly Reactive Sodium Tripolyphosphate in the Absence of Catalyst
}

\author{
Xiaoyu Zhang ${ }^{1}$, Lei Luo ${ }^{1}$, Huaibin Kang ${ }^{1}$, Xinfang Liu $^{2 \star}$, Wenxue Zhu ${ }^{1 \star}$ and Xina \\ $\mathrm{Yu}^{1}$ \\ ${ }^{1}$ Food \& Bioengineering Department, Henan University of Science and Technology, Luoyang, Henan 471003, ${ }^{2}$ College of \\ Chemistry and Chemical Engineering, Luoyang Normal University, Luoyang, Henan 471022, PR China
}

*For correspondence: Email: liuxinfang6@126.com; Tel: +86-379-69810219; Fax: +86-379-69810219

\begin{abstract}
Purpose: To prepare edible corn starch phosphate under optimized experimental conditions. Methods: Edible corn starch phosphate was prepared via the reaction of starch with active sodium tripolyphosphate. Reaction efficiency and viscosity were used as indices to optimize experimental conditions. Freeze-thaw stability and transparency of starch phosphate and native starch were comparatively studied.

Results: Starch phosphate with optimal combined phosphate content (0.39\%) was obtained under optimized conditions: reaction duration, $90 \mathrm{~min}$; temperature, $160 \mathrm{oC} ; \mathrm{pH}, 5.0$; and phosphate, $1.5 \mathrm{~g}$. Starch phosphate with optimal viscosity $(230 \mathrm{cp})$ was obtained under different conditions: reaction duration, $120 \mathrm{~min}$; temperature, $140 \mathrm{oC}$; $\mathrm{pH}, 6.0$; and phosphate, $1.5 \mathrm{~g}$. Significant differences $(p<$ $0.05)$ were observed in syneresis and paste transparency of starch phosphate and native starch.

Conclusion: Edible corn starch phosphate has been successfully prepared under optimized experimental conditions whose freeze-thaw stability and paste transparency has obvious improvement compared with native starch.
\end{abstract}

Keywords: Starch phosphate, Combined phosphate, Sodium tripolyphosphate, Syneresis, Paste efficiency

Tropical Journal of Pharmaceutical Research is indexed by Science Citation Index (SciSearch), Scopus, International Pharmaceutical Abstract, Chemical Abstracts, Embase, Index Copernicus, EBSCO, African Index Medicus, JournalSeek, Journal Citation Reports/Science Edition, Directory of Open Access Journals (DOAJ), African Journal Online, Bioline International, Open-J-Gate and Pharmacy Abstracts

\section{INTRODUCTION}

Starch phosphate, one of the esterified starches, is produced from esterification of starch and phosphate. In food industry, starch phosphate can replace some colloids as thickener and stabilizer used in flour products, meat, soup or drink products because it has high viscosity, freeze-thaw stability and anti-aging resistance [13]. Usually, starch phosphate is prepared with phosphate as esterifying agent and urea as catalyst $[4,5]$. However, the use of harmful urea makes the target product unsuitable for human consumption.

Herein, highly reactive sodium tripolyphosphate (STP) was used as esterifying agent to react with starch to prepare edible corn starch phosphate in the absence of catalyst (urea). Through single factor tests and orthogonal experiments, we confirm the optimized reaction conditions of starch phosphate with the optimal combined phosphate content and that with the optimal paste viscosity. In the meanwhile, paste 
transparency and freeze-thaw stability of the prepared starch phosphate and native starch are comparatively studied.

\section{EXPERIMENTAL}

\section{Materials}

Ordinary corn starch was purchased from Shandong Shou Guang Corn Starch Company. Sodium tripolyphosphate (STP, chemical pure), sodium hydrogen phosphate (analytical pure) and sodium dihydrogen phosphate (analytical pure) were purchased from Shanghai Chemical Reagent Company.

\section{Main equipment}

High-speed homogenate machine, Jiangsu Jintan Rong Hua Instrument Manufacture Company; Oven, Xinli Instrument Manufacture Factory; pHs - 3c Precision pH meter, Shanghai Ray Magnetic Instrument Factory; DZF - 6010 vacuum drying oven, Henan Gongyi Yingyu Yuhua Instrument Factory; 752 Ultraviolet grating spectrophotometer, Shanghai Third Analysis Instrument Factory; Micro sprayer, self-made; NDJ - 9 viscometer, Shanghai Shangtian Precision Instrument Company.

\section{Preparation of starch phosphate}

A certain quality of STP was dissolved in $10 \mathrm{ml}$ of water and $\mathrm{pH}$ value was adjusted to a certain value. The sample was sprayed evenly on to 100 $\mathrm{g}$ dried starch after dissolving completely. The mixture was stirred about $30 \mathrm{~min}$ in a homogenate machine and the product was obtained after reaction at certain temperature for certain duration. At last the product was washed with water and filtered.

The effects of $\mathrm{pH}$ value, reaction temperature, reaction duration and added amount of phosphate on reaction efficiency and viscosity of starch phosphate were examined through single factor experiments. The orthogonal experiments were designed according to the results of single factor tests. The level of design factors are shown in Table 1, choosing $L_{9}\left(3^{4}\right)$ to arrange the experiment.

\section{Determination of combined phosphorus content of starch phosphate}

The total phosphorus content (phosphorus content of unwashed product) was measured according to GB 12092-89.

Free phosphorus refers to the phosphorus existing in the form of inorganic phosphorus, which mainly comes from the incomplete reaction of esterifying agent with starch. Assay method is as follows: $1.0 \sim 2.0 \mathrm{~g}$ sample was put into a 50 $\mathrm{ml}$ beaker and dissolved with $1 \mathrm{~mol} / \mathrm{L}$ hydrochloric acid. And then it was transferred into a $250 \mathrm{ml}$ volumetric flask, diluted with water to volume, shaken well and filtered for use. The filtrate $(5 \sim 10 \mathrm{ml})$ was transferred into a $50 \mathrm{ml}$ conical flask. Color reaction was manipulated according to GB 12092-89 and the phosphorus content was determined by measuring the light absorbance.

Combined phosphorus content is the difference between total phosphorus content and free phosphorus content.

\section{Determination of reaction efficiency}

Reaction efficiency (RE) was calculated according to Eq 1.

$\operatorname{RE}(\%)=(X 1-Y) /(Y 1-Y) \times 100$

Where $\mathrm{X} 1=$ combined phosphorus content of starch phosphate, $Y=$ total phosphorus content of native starch, and $\mathrm{Y} 1=$ total phosphorus content of starch phosphate.

\section{Performance test}

Viscosity was measured according to GB 1209889. Freeze-thaw stability (syneresis \%) was measured according to literature [6]. Paste transparency was measured according to literature [7].

Table 1: Factors and levels during preparation of starch phosphate

\begin{tabular}{lcccc}
\hline Factor & $\begin{array}{c}\text { Reaction duration } \\
\mathbf{A}(\mathbf{m i n})\end{array}$ & $\begin{array}{c}\text { Reaction temperature } \\
\mathbf{B}\left({ }^{\circ} \mathbf{C}\right)\end{array}$ & $\begin{array}{c}\text { pH value } \\
\text { C }\end{array}$ & $\begin{array}{c}\text { Added amount of phosphate } \\
\mathbf{D}(\mathbf{g})\end{array}$ \\
\hline 1 & 60 & 120 & 5.0 & 0.5 \\
2 & 90 & 140 & 5.5 & 1.0 \\
3 & 120 & 160 & 6.0 & 1.5 \\
\hline
\end{tabular}




\section{Statistical analysis}

The results are reported as mean $\pm S D(n=3)$. Differences were determined using Duncan's new multiple range test. Single factor and other experiments for means and differences were set $p<0.05$. All data were statistically analyzed using SPSS software (version 12.0; SPSS Inc, Chicago, IL, USA).

\section{RESULTS}

\section{Optimized experimental conditions}

The effects of added amount of phosphate, $\mathrm{pH}$ value, reaction temperature and reaction duration on reaction efficiency and viscosity of starch phosphate are initially determined through single factor experiment and the results are shown in Figures $1 \sim 4$. The optimal conditions were as follows: phosphate $<1.5 \mathrm{~g}$; $\mathrm{pH}$ : 5.5 ; temperature: $<160^{\circ} \mathrm{C}$; reaction duration: $<2 \mathrm{~h}$.

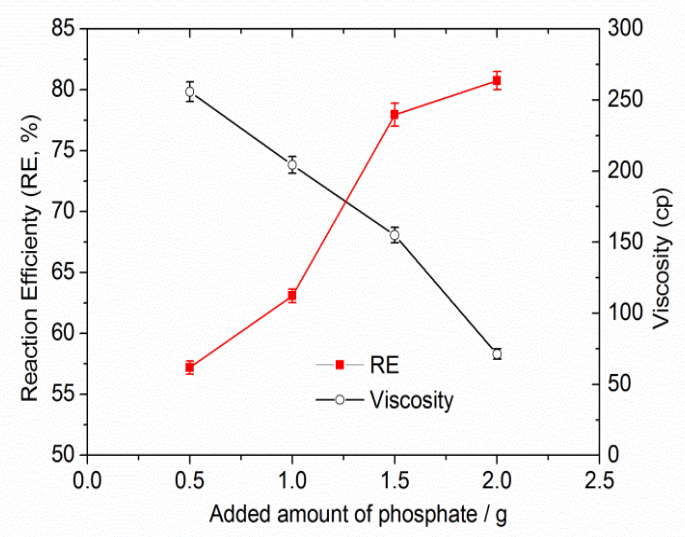

Figure 1: Effect of adde amounts of phosphate on the esterification reaction ( $\mathrm{pH}$ : 5.5 ; temperature: $140^{\circ} \mathrm{C}$; reaction duration: $2 \mathrm{~h}$ )

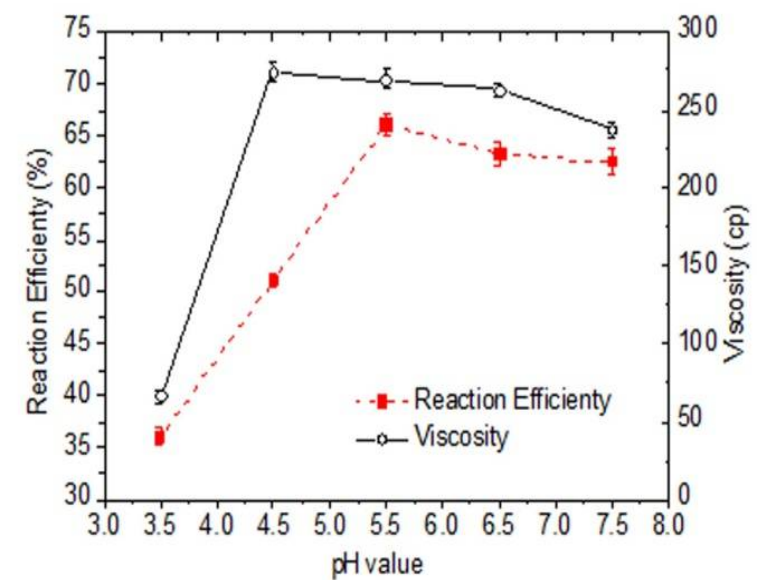

Figure 2: Effect of $\mathrm{pH}$ value on the esterification reaction (phosphate: $1.5 \mathrm{~g}$; temperature: $140{ }^{\circ} \mathrm{C}$; reaction duration: $2 \mathrm{~h}$ )

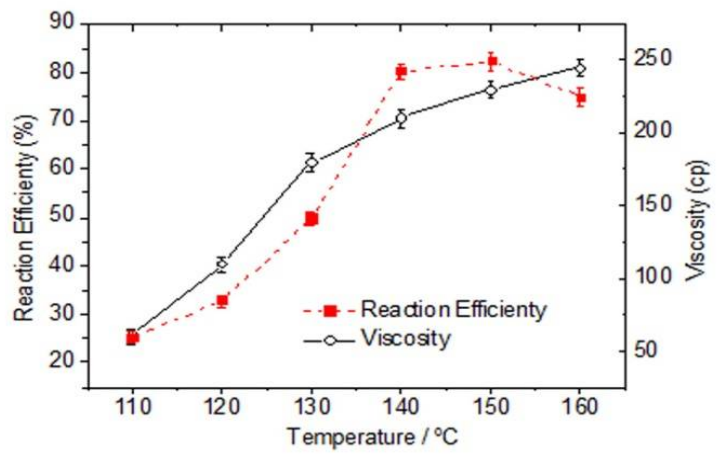

Fig 3: Effect of reaction temperature on the esterification reaction (phosphate: $1.5 \mathrm{~g}$; $\mathrm{pH}$ : 5.5; reaction duration: $2 \mathrm{~h}$ )

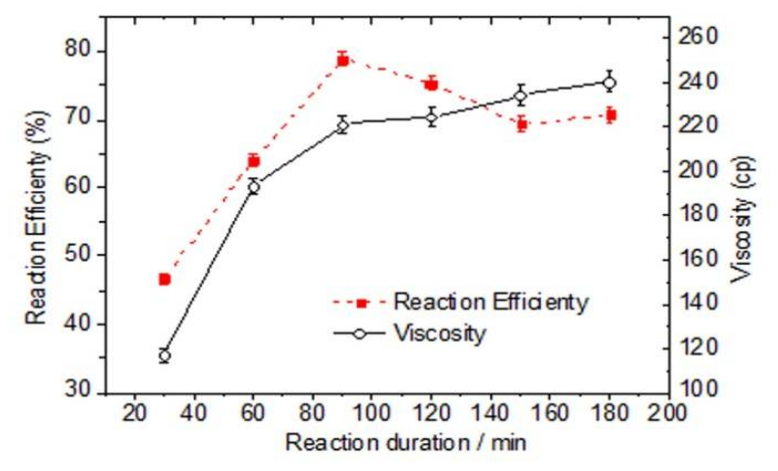

Figure 4: Effect of reaction duration on the esterification reaction (phosphate: $1.5 \mathrm{~g}$; $\mathrm{pH}$ : 5.5; temperature: $140{ }^{\circ} \mathrm{C}$ )

The results of orthogonal design experiments are shown in Table 2. Statistically significant differences are observed in the combined phosphate content and viscosity of starch phosphate prepared under different conditions. According to the table, the reaction conditions for starch phosphate with optimal combined phosphorus content $(0.39 \%)$ are A2B3C1D3. That is, the reaction conditions are optimized as follows: reaction duration: 90min; temperature: $160{ }^{\circ} \mathrm{C} ; \mathrm{pH}, 5.0$; phosphate, $1.5 \mathrm{~g}$. The reaction conditions for starch phosphate with the best viscosity $(230 \mathrm{cp})$ are A3B2C3D3. It means the optimized reaction conditions are as follows: reaction duration: $120 \mathrm{~min}$; temperature: $140{ }^{\circ} \mathrm{C}$; $\mathrm{pH}, 6.0$; phosphate, $1.5 \mathrm{~g}$.

\section{Performance data for phosphates and native starch}

Statistically significant differences also occurred in transparency and freeze-thaw stability of starch phosphates prepared under optimal reaction conditions and native starch (Table 3 ). The results show that starch phosphate has high viscosity, freeze-thaw stability and paste transparency compared with native starch. 
Table 2: The orthogonal experimental results of starch phosphate

\begin{tabular}{ccc}
\hline Experimentno. & Combined phosphate content (\%) & Viscosity (cp) \\
\hline 1 & $0.059 \pm 0.002^{\mathrm{e}}$ & $53 \pm 4.0^{\mathrm{g}}$ \\
2 & $0.13 \pm 0.005^{\mathrm{a}}$ & $110 \pm 4.7^{\mathrm{e}}$ \\
3 & $0.33 \pm 0.007^{\mathrm{b}}$ & $208 \pm 7.5^{\mathrm{b}}$ \\
4 & $0.27 \pm 0.006^{\mathrm{c}}$ & $195 \pm 6.2^{\mathrm{b}}$ \\
5 & $0.14 \pm 0.006^{\mathrm{a}}$ & $85 \pm 4.7^{\dagger}$ \\
6 & $0.27 \pm 0.007^{\mathrm{c}}$ & $160 \pm 5.2^{\mathrm{c}}$ \\
7 & $0.13 \pm 0.004^{\mathrm{a}}$ & $150 \pm 5.0^{\mathrm{ca}}$ \\
8 & $0.39 \pm 0.007^{\mathrm{a}}$ & $230 \pm 7.8^{\mathrm{a}}$ \\
9 & $0.14 \pm 0.004^{\mathrm{a}}$ & $140 \pm 4.8^{\mathrm{a}}$ \\
\hline
\end{tabular}

Table 3: Performance results for starch phosphate and native starch

\begin{tabular}{lccc}
\hline Variable & Syneresis (\%) & $\begin{array}{c}\text { Paste transparency } \\
\text { (\%) }\end{array}$ & $\begin{array}{c}\text { Viscosity } \\
\text { (cp) }\end{array}$ \\
\hline Native corn starch & $65 \pm 2.5^{\mathrm{a}}$ & $11 \pm 0.3^{\mathrm{c}}$ & $40 \pm 3.2^{\mathrm{c}}$ \\
Starch phosphate with the optimal combined & $46 \pm 1.9^{\mathrm{b}}$ & $28 \pm 0.5^{\mathrm{a}}$ & $210 \pm 7.4^{\mathrm{b}}$ \\
phosphorus & $42 \pm 1.8^{\mathrm{b}}$ & $24 \pm 0.5^{\mathrm{b}}$ & $255 \pm 8.3^{\mathrm{a}}$ \\
\hline Starch phosphate with the best viscosity & $42 \pm$
\end{tabular}

\section{DISCUSSION}

Figure 1 shows that added amount of phosphate $(0.5,1.0,1.5,2.0 \mathrm{~g})$ has great influence on reaction efficiency. With the increase of phosphate, the reaction efficiency of starch phosphate is on the decline while the viscosity is increased. When the dosage of phosphate increases from $1.5 \mathrm{~g}$ to $2.0 \mathrm{~g}$, the viscosity increases a little while the reaction efficiency decreases much. More importantly, when the added amount of phosphate was $2.0 \mathrm{~g}$, the combined phosphorus content is more than 0.4 $\%$, which is the maximum amount prescribed by the Food and Drug Administration (FDA). And thus, the best addition of phosphate is $1.5 \mathrm{~g}$. The effects of $\mathrm{pH}$ value $(3.5,4.5,5.5,6.5$ and 7.5$)$ were shown in Figure 2. The figure indicates that when the $\mathrm{pH}$ value raises from 3.5 to 4.5 , the reaction efficiency increased from $39 \%$ to $71 \%$ and the viscosity increases from 40 to $140 \mathrm{cp}$; when $\mathrm{pH}$ raises to 5.5 , the reaction efficiency decreases little while the viscosity is as high as $240 \mathrm{cp}$; when the $\mathrm{pH}$ value is greater than 5.5 , the reaction efficiency and viscosity tend to decrease. Accordingly, the appropriate $\mathrm{pH}$ is about 5.5.

The effects of reaction temperature $(110,120$, $130,140,150$ and $160{ }^{\circ} \mathrm{C}$ ) were shown in Figure 3 . As can be seen from Figure 3 , the reaction efficiency is low under $110^{\circ} \mathrm{C}$. With the increase of reaction temperature, reaction efficiency is gradually increased. From $110{ }^{\circ} \mathrm{C}$ to $140{ }^{\circ} \mathrm{C}$, the product viscosity is on the rise. From 140 to 150 ${ }^{\circ} \mathrm{C}$, the increase of viscosity is very small and the viscosity decreases at $160^{\circ} \mathrm{C}$. In addition, when reaction temperature is higher than $160{ }^{\circ} \mathrm{C}$, the product color will be yellow, affecting the appearance of the starch. Therefore, the appropriate temperature should not be higher than $160^{\circ} \mathrm{C}$.

Effect of reaction duration $(0.5,1.0,1.5,2.0,2.5$ and 3.0 hours) was determined and shown in Figure 4. As can be seen from Figure 4, reaction duration and reaction efficiency are positively correlated from $30 \mathrm{~min}$ to $90 \mathrm{~min}$. When the reaction duration increases from $90 \mathrm{~min}$ to 3.0 hours, the reaction efficiency is increased slowly and the viscosity is decreased gradually. Long reaction duration will also deepen the color of starch phosphates, making unfavorable performance of the final product. For reasons given above as well as the perspective of saving energy, it is advisable to choose the reaction duration not higher than $120 \mathrm{~min}$.

On the basis of single-factor experiments, an orthogonal experiment was carried out. The reaction conditions for the preparation of starch phosphate with optimal combined phosphorus content $(0.39 \%)$ are optimized. The reaction conditions for starch phosphate with the best viscosity $(238 \mathrm{cp})$ are the same with the former except for the reaction temperature. The results of transparency and freeze-thaw stability show that the prepared starch phosphates have high viscosity, freeze-thaw stability and paste transparency compared with native starch. And thus, corn starch phosphate is more suitable for use as a thickener in food industry.

\section{CONCLUSION}

Starch phosphate with optimal combined phosphorus content $(0.39 \%)$ and starch phosphate with the optimal viscosity $(255 \mathrm{cp})$ 
have been successfully prepared under optimized reaction conditions. Compared with native starch, corn starch phosphate is more effective as a thickener in food industry because it has great improvement in viscosity, freezethaw stability and paste transparency.

\section{ACKNOWLEDGEMENT}

The authors are grateful for the financial support from the National Natural Science Foundation of China (nos. 31401654 and 21302082), Henan University of Science and Technology Dr Startup Funds (no. 09001744) and Henan University of Science and Technology Fund (no. 13470099).

\section{REFERENCES}

1. Pająk $P$, Fortuna $T$, Gałkowska D. Rheological characteristics of sour cherries in gels containing waxy maize and cassava starches. J. Food Qual. 2012; 35(6), 401-410.

2. Passauer L, Liebner F, Fischer K. Synthesis and properties of novel hydrogels from cross-linked starch phosphates. Macromol. Symp. 2006; 244(1): 180-193.
3. Ptaszek A. The role of characteristic times in rheological description of structure forming food additives. J. Food Eng. 2012; 111(2): 272-278.

4. Liu Z, Yan Y, Gao X, Gao L. Study on the preparation of wheat starch phosphate with low degree of substitution. Phosphorus, Sulfur Silicon Relat. Elem. 2008; 183(2-3): 547-554.

5. Wei M, Liu Y, Liu B, Lv X, Sun P, Zhang Z, Zhang F, Yin $S$, Liu Z. Preparation and application of starch phosphate with a low degree of substitution. Phosphorus, Sulfur Silicon Relat. Elem. 2011; 186(4): 974-982.

6. Arunyanart $T$, Charoenrein S. Effect of sucrose on the freeze-thaw stability of rice starch gels: Correlation with microstructure and freezable water. Carbohyd. Polym. 2008; 74(3): 514-518.

7. Jacobson MR, Obanni M, Bemiller JN. Retrogradation of starches from different botanical sources 1. Cereal Chem. 1997; 74(5): 511-518.

8. Grant $\mathrm{RH}$, Mertens $\mathrm{DR}$. Influence of buffer $\mathrm{pH}$ and raw corn starch addition on in vitro fiber digestion kinetics. J. Dairy Sci. 1992; 75(10): 2762-2768.

9. Guska E, Khan K. Effect of temperature on properties of extrudates from high starch fractions of navy, pinto and garbanzo beans. J. Food Sci. 1990; 55(2): 466-469. 